\title{
Genome wide characterization of WUSCHEL-related homeobox (WOX) gene family in Apostasia shenzhenica, a primeval orchid
}

\author{
Thakku R Ramkumar, Madhvi Kanchan \& Jaspreet K. Sembi* \\ Department of Botany, Panjab University, Chandigarh 160 014, India \\ *Email: jaspreet.sembi@pu.ac.in
}

\section{ARTICLE HISTORY}

Received: 12 September 2019

Accepted: 19 February 2020

Published: 01 April 2020

\section{KEYWORDS}

Apostasia shenzhenica; WUSCHEL; WOX

\section{GUEST EDITOR}

Dr. Nyuk Ling Ma

Universiti Malaysia Terengganu

\begin{abstract}
In the present study, we report identification and characterization of the plant-specific WUSCHELrelated homeobox (WOX) gene family in Apostasia shenzhenica, a primeval orchid. WOX proteins are DNA-binding WUSCHEL-related homeobox (WOX) encoding transcription factors that play critical role in zygote patterning, embryo development, organogenesis, florigenesis, stress responses etc. Ten putative AsWOX genes were predicted in the $A$. shenzhenica genome and were characterized by the presence of DNA-binding helix-loop-helix-turn-helix motif. AsWOX proteins were grouped into three clades, ancient, intermediate and WUS on the basis of sequence homology with Arabidopsis thaliana (AtWOX), Oryza sativa (OsWOX), Phalaenopsis equestris (PeWOX) and Dendrobium catenatum (DcWOX) and their phylogenetic relationship was established. Gene structure analysis revealed that three AsWOX genes had two introns, six genes had a single intron, and one gene was intron-less. Expression profiling in a variety of tissue (tubers, seeds and pollens) was analysed in light of the presence of specific cisregulatory elements in the promoter region and their role in various developmental processes was discussed. Three dimensional structures were predicted for three selected AsWOX proteins representing the three clades. The present study provides insights to the role of AsWOX gene family in various vital developmental processes, establishes phylogenetic relationships with related plant species and provides a platform for functional validation of specific AsWOX genes.
\end{abstract}

\section{Introduction}

The WUSCHEL-related homeobox (WOX) gene family is involved in plant embryonic patterning, stem cell maintenance, organogenesis, florigenesis, somatic embryogenesis and stress responses (1-3). These genes encode plant specific DNA-binding homeobox transcription factors which are characterized by $60-66$ amino acid (aa) residues long homeobox domain with embedded DNA-binding helix-loop-helix-turn-helix motif $(4,5)$. Based on sequence homology, WOX proteins can be classified into three clades, Ancient, Intermediate and WUS (1). The Ancient clade evolved earlier and can be found from algae to angiosperms. The Intermediate clade emerged after the origin of pteridophytes and is absent in algae and bryophytes. The WUS clade, on the other hand, is found only in angiosperms, indicating that it is the most advanced clade (1).
WUS gene was first identified in Arabidopsis thaliana, with roles in shoot and floral apices development by maintaining the stem cell potency (6). Later, several of WOX genes were functionally characterized in other organism ranging from algae to flowering plants, such as Ostreococcus tauri, $O$. lucimarinus and Physcomitrella patens (7), Selaginella kraussiana and S. moellendorffii (8), Picea abies (9), Arabidopsis thaliana (7), Populus trichocarpa (10), Solanum lycopersicum (11), Monotropa hypopitys (12), Broussonetia papyrifera (13), Prunus persica, P. mume, Pyrus bretschneideri and Fragaria vesca (14), Vitis vinifera (15), Gossypium arboreum, G. raimondii and $G$. hirsutum (16), Cucumis sativus, C. melo and Citrullus lanatus (17), Oryza sativa, Zea mays and Sorghum bicolour (10), Ananas comosus (18), Phalaenopsis equestris and Dendrobium catenatum (19), Salix suchowensis (20), Camellia sinensis (21), Brassica napus,

(C) Ramkumar et al. (2020). This is an open-access article distributed under the terms of the Creative Commons Attribution License, which permits unrestricted use, distribution, and reproduction in any medium, provided the original author and source are credited (https://creativecommons.org/licenses/by/4.0/).

To cite this article: Ramkumar TR, Kanchan M, Sembi JK. Genome wide characterization of WUSCHEL-related homeobox (WOX) gene family in Apostasia shenzhenica, a primeval orchid. Plant Science Today. 2020;7(2):164-171. https://doi.org/10.14719/pst.2020.7.2.703 
Table 1. Characterization of AsWOX protein sequences

\begin{tabular}{|c|c|c|c|c|c|c|c|c|c|c|}
\hline Gene & NCBI ID & $\mathbf{A A}$ & MW & pI & Ins & AI & GRAVY & Loc & SP & TMD \\
\hline AsWOX12 & $\begin{array}{l}\text { PKA61831.1 } \\
\end{array}$ & 204 & 22.48 & 9.41 & 72.46 & 75.05 & -0.375 & Nuclear & No & $\overline{0}$ \\
\hline AsWOX11 & PKA58526.1 & 148 & 15.83 & 9.5 & 67.26 & 72.43 & -0.223 & Nuclear & No & 0 \\
\hline AsWOX9 & PKA48738.1 & 349 & 37.31 & 6.31 & 62.41 & 74.76 & -0.351 & Nuclear & No & $\overline{0}$ \\
\hline AsWOX13 & PKA60098.1 & 245 & 27.74 & 8.2 & 46.17 & 58.49 & -0.787 & Nuclear & No & $\overline{0}$ \\
\hline AsWOX2A & PKA63241.1 & 248 & 27.57 & 9.52 & 67.65 & 67.66 & -0.697 & Nuclear & No & $\overline{0}$ \\
\hline AsWOX2B & PKA48554.1 & 258 & 27.26 & 5.99 & 66.67 & 50.08 & -0.721 & Nuclear & No & 0 \\
\hline AsWOX3A & PKA49032.1 & 207 & 23.19 & 9.03 & 68.39 & 55.65 & -0.757 & Nuclear & No & 0 \\
\hline AsWOX3B & PKA46270.1 & 215 & 23.86 & 7.11 & 60.11 & 66.84 & -0.593 & Nuclear & No & 0 \\
\hline AsWUS & PKA53419.1 & 268 & 29.02 & 6.5 & 64.63 & 50.37 & -0.724 & Nuclear & No & 0 \\
\hline AsWOX7 & PKA52499.1 & 137 & 16.13 & 10.44 & 72.83 & 67.59 & -0.958 & Nuclear & No & 0 \\
\hline
\end{tabular}

Isoelectric point (pI), protein molecular weight (MW) in $\mathrm{kDa}$, instability index (Ins), aliphatic index (AI) grand average of hydropathy (GRAVY), localization (Loc), signal Peptide (SP) transmembrane domain (TMD)
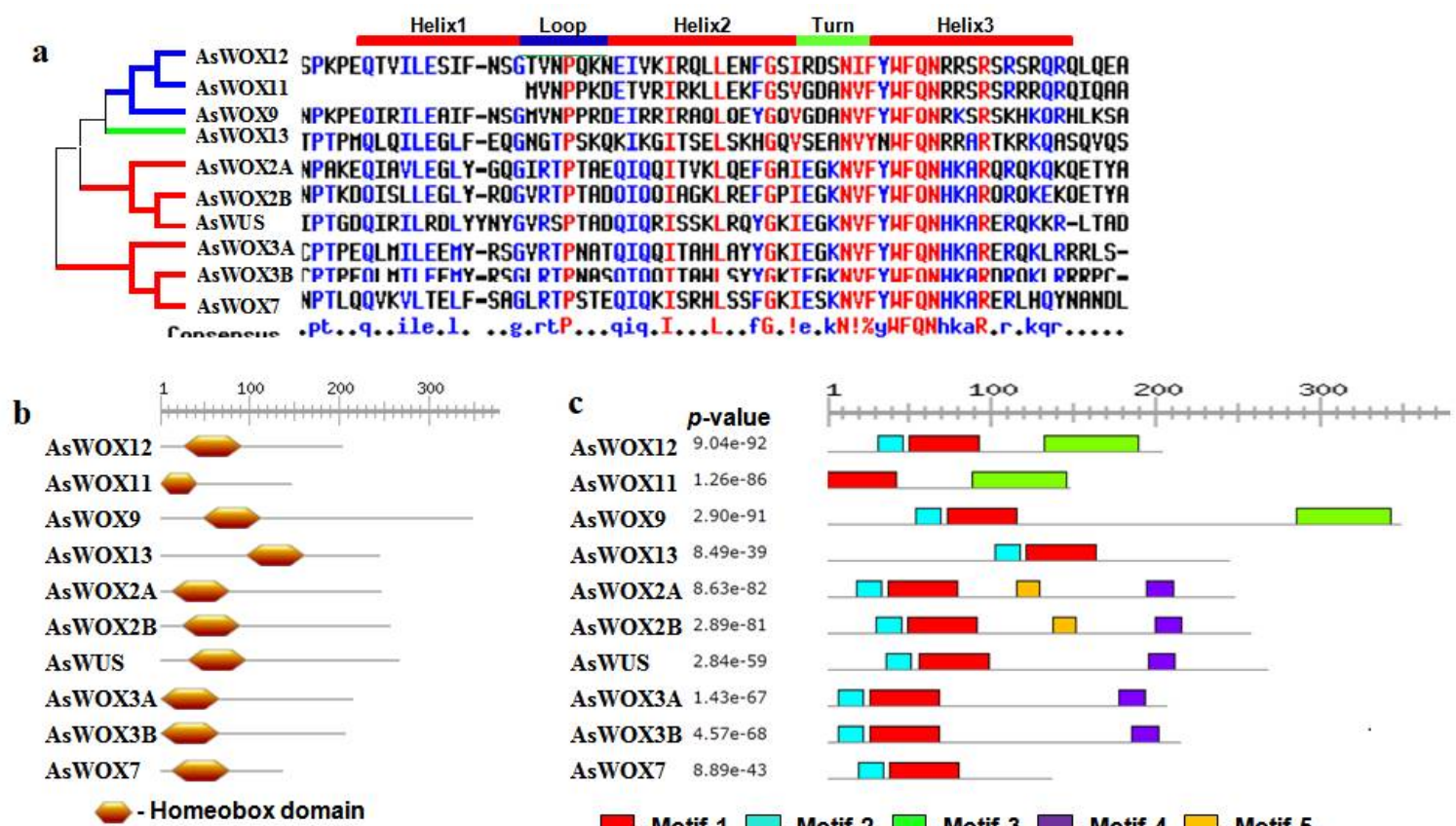

\section{-Motif $1 \square$-Motif $2 \square$-Motif $3 \square$-Motif $4 \square$-Motif 5}

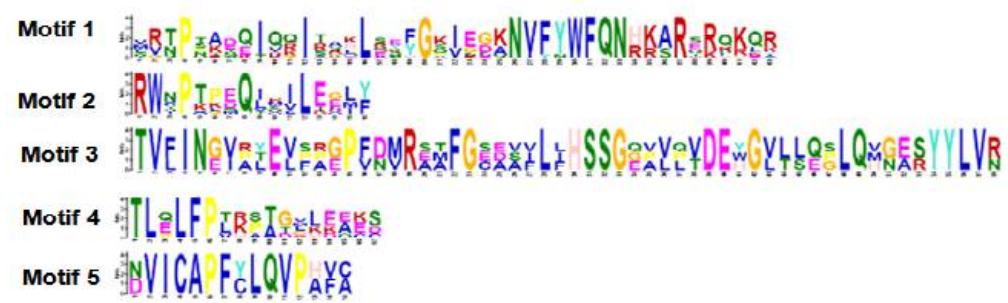

Fig. 1. Domain and motif analyses in AsWOX proteins: a. Multiple sequence alignment of AsWOXs, the DNA-binding helix-loop-helix-turnhelix region is marked; b. Representation of homeobox domain; c. Identified conserved motifs are marked in coloured boxes and sequence logo of these motifs showing degree of conservation at each amino acid position.

Brassica rapa and Brassica oleracea (22) and Juglans regia (23).

In post-genomics era, genome-wide characterizations of gene families are prevalent in crop plants, however, such studies are scarce in orchids as only a few orchid genomes have been sequenced so far (24-26). For the present work, $A$. shenzhenica, a primeval terrestrial orchid, was selected because of its evolutionarily significance as it represents the most primitive subfamily, Apostasioideae which has strong divergence from Orchidaceae. This taxa is characterized by actinomorphic flowers, indistinct labellum, rudimentary gynostemium, absence of pollinia and non-resupinating ovary which are contrasting to the general characteristics of orchids (27). Thus, it is important to study the plant in order to evaluate its evolutionary status and relationship. In this report, a genome-wide analysis was done to study physicochemical characterization, structure prediction, phylogenetic relationships, analysis of cis-regulatory elements and spatio-temporal expression profiling of AsWOX gene family. The study would pave way for functional characterization of WOX genes and provide insights for their potential role in growth and development of orchids. 


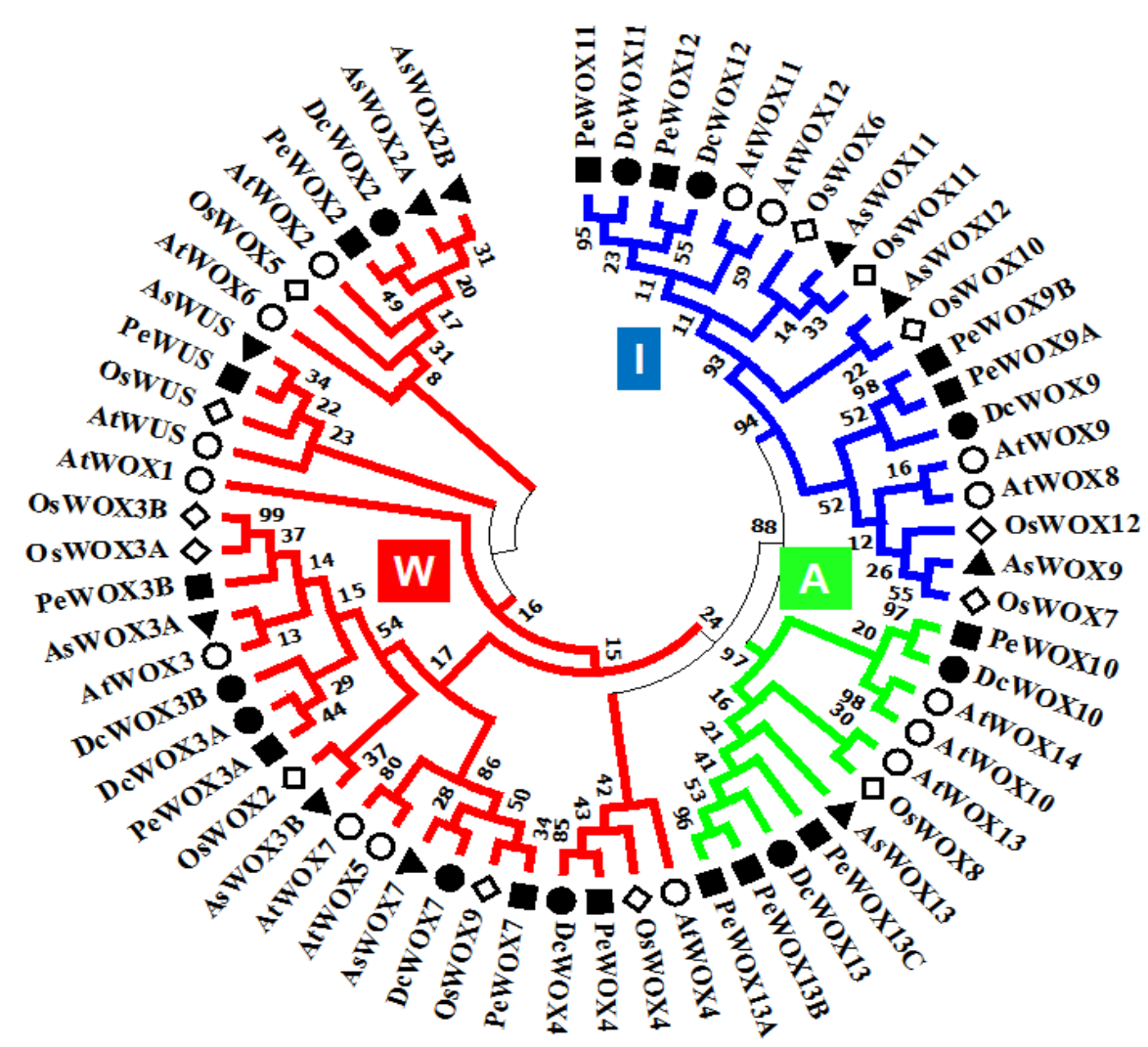

Fig. 2. Phylogenetic analysis of AsWOXs proteins: Phylogenetic tree with the sequences of AsWOX with PeWOX (P. equestris), DcWOX (D. catenatum), AtWOX (A. thaliana) and OsWOX (O. sativa) showing grouping into three distinct clades, ancient (A), intermediate (I) and WUS (W) marked in green, blue and red respectively.

Table 2. Gene scaffold and gene stretch region with NCBI ID of AsWOX genes

\begin{tabular}{rlll}
\hline & Gene & Gene Scaffold & Gene Stretch \\
\hline 1 & AsWOX12 & fragScaff_scaffold_40 & KZ451923.1:2177800-2179273 \\
\hline 2 & AsWOX11 & fragScaff_scaffold_68 & KZ451951.1:c777337-775757 \\
\hline 3 & AsWOX9 & original_scaffold_327 & KZ452209.1:176088-178201 \\
\hline 4 & AsWOX13 & fragScaff_scaffold_59 & KZ451942.1:c2215404-2208264 \\
\hline 5 & AsWOX2A & fragScaff_scaffold_26 & KZ451909.1:307739-310274 \\
\hline 6 & AsWOX2B & original_scaffold_431 & KZ452313.1:c950380-948698 \\
\hline 7 & AsWOX3A & fragScaff_scaffold_158 & KZ452041.1:c426344-424274 \\
\hline 8 & AsWOX3B & original_scaffold_2507 & KZ454389.1:c500918-499419 \\
\hline 9 & AsWUS & fragScaff_scaffold_115 & KZ451998.1:c1564267-1563301 \\
\hline 10 & AsWOX7 & fragScaff_scaffold_119 & KZ452002.1:c793199-792786 \\
\hline
\end{tabular}

The prefix ' $c$ ' in gene stretch region represents the presence of gene complementary strand

\section{Materials and Methods}

\section{Identification of WOX family proteins}

The WOX protein sequences of Arabidopsis thaliana (AtWOXs), Oryza sativa (OsWOXs), Phalaenopsis equestris (PeWOX) and Dendrobium catenatum (DcWOX) $(1,10,19)$ were used as query sequences and Blastp was carried out against the NCBI derived Apostasia shenzhenica protein database; taxid:1088818). The retrieved AsWOX sequences were then analysed for the presence of WUSCHEL-related homeobox (pfam00046) domain using SMART server (28) and the domain architecture was constructed using Expasy - Prosite server (29). To locate the DNAbinding helix-loop-helix-turn-helix domain, multiple sequence alignment using MULTALIN tool (30) was done. The conserved motifs were identified using MEME suite server (31), with preset parameters (maximum number of motifs - 05, number of repetitions - any, optimum motif width - $\geq 6$ and $\leq 200$ ).

\section{Phylogenetic analysis}

Full length protein sequences (AsWOX, PeWOX, DcWOX, AtWOX and OsWOX) were initially aligned with MUSCLE program and the phylogenetic tree was then constructed using MEGA7 tool (32) by maximumlikelihood method at bootstrap value of 1000 .

\section{Physico chemical characterization}

The AsWOX sequences were analysed using the Expasy-ProtParam server (33) to calculate the physico chemical properties such as molecular weight, 


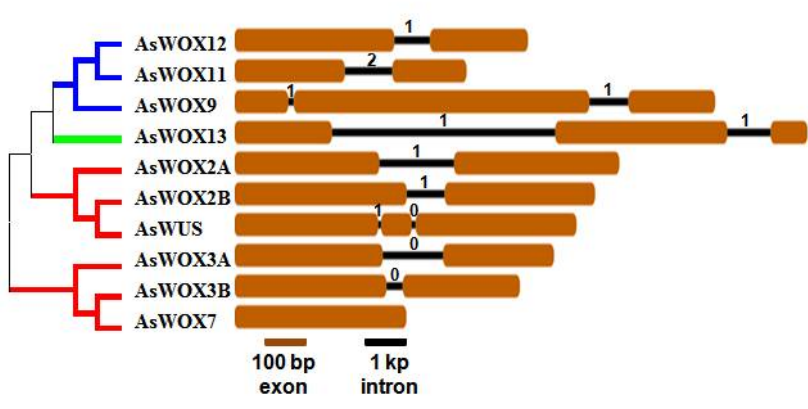

Fig. 3. Structural organisation of AsWOX genes: Exon-intron organization showing exons marked as boxes and introns as lines. Intronic phases 01 and 2 are also represented.

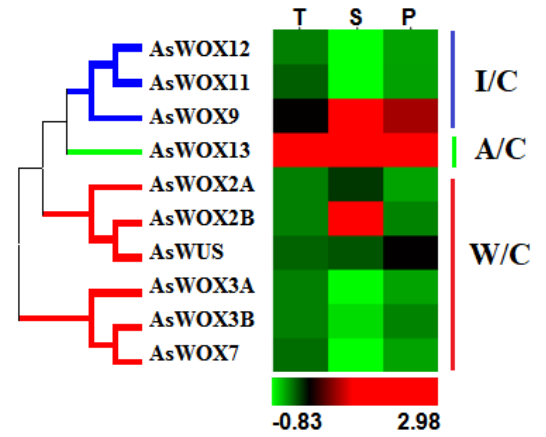

Fig. 4. Expression profile of AsWOX genes: Spatiotemporal expression of AsWOX genes shown in the Heat map in various tissues, tuber (T), seed (S), and pollen (P)

Table 3. Secondary structure and ligand binding sites in selected AsWOX proteins

\begin{tabular}{|c|c|c|c|c|c|}
\hline Protein & Alpha helix & Random coil & Extended strand Beta turn & Ligand & Ligand binding sites \\
\hline WOX13 & $32.24(79)$ & 52.65 (129) & $8.98(22)$ & Nucleic acid & $\begin{array}{l}100,101,102,103,104,106,147,150, \\
151,154,158\end{array}$ \\
\hline WOX9 & $22.92(80)$ & $61.60(215)$ & $11.17(39)$ & Nucleic acid & $106,109,110$ \\
\hline WOX2B & $20.16(52)$ & $62.79(162)$ & $11.63(30)$ & Glycerol & 82,85 \\
\hline
\end{tabular}

Values indicate: \% of amino acids (No. of amino acids are shown in brackets)

aliphatic index, instability index, $\mathrm{pI}$ and grand average of hydropathicity (GRAVY). Online tools such as Signal P.4.0 (34) and TMHMM v.2.0 (35) were used to detect the signal peptide and transmembrane region CELLO v.2.5 (36), WoLF PSORT (37), TargetP-2.0 (38) and Plant-mPLoc (39) were used to predict the sub-cellular localization.

\section{Gene structure and cis-regulatory elements analyses}

For each AsWOX protein sequence, coding sequence (CDS) and gene sequence were retrieved from NCBI database. The gene structure with exon-intron display was drawn using Gene Structure Display Server 2.0 (40). The promoter regions were retrieved from $1.5 \mathrm{~kb}$ upstream sequences of the genes, from NCBI database and the presence of cis-regulatory elements was confirmed using PLACE server (41). Promoter elements were further analysed to identify common and specific promoter elements using Venn Diagram tool.

\section{Gene duplication events and ortholog prediction}

The sequence similarity index among AsWOX CDS sequences were obtained using MUSCLE tool (42), and the genes sharing $\geq 80 \%$ identity were considered duplicated. To predict the ortholog proteins, a local NCBI BLASTp search was performed with each candidate AsWOX protein sequences querying independently against the WOX protein sequences of target species i.e. A. thaliana (AtWOX), O. sativa (OsWOX), P. equestris (PeWOX) and D. catenatum (DcWOX), and the orthologs were identified.

\section{Expression analysis}

The AsWOX CDS sequences were used for BLASTn search against the high throughput RNA-seq data for various developmental stages like tuber (SRX2938654), seed (SRX2938653) and pollen (SRX2938652) of $A$. shenzhenica available from NCBI database (26). The hits were counted and the RPKM values (Reads per
Kilobase per Million) were calculated using the formula RPKM $=\left(\mathrm{C} \times 10^{9}\right) /(\mathrm{N} \times \mathrm{L})$, in which $\mathrm{C}$ represents number of hits for the candidate gene, $\mathrm{N}$ represents total mapped reads in the concerned RNAseq experiment and L represents the length of gene in base-pairs (43). The heat maps to visualise the differential expression of were generated using Hierarchical Clustering Explorer 3.5 (44).

\section{Molecular modelling}

The secondary structure of AsWOX proteins was analysed using the online tool SOPMA secondary structure prediction (45), for the presence of alpha helices, random coils, beta turns and extended strands. For prediction of tertiary structure, I-Tasser, a molecular modelling tool (46) was used by simulating with top 10 closely related homologous templates in PDB (Protein Data Bank) with the help of BS-scores, TM-scores, IDEN coverage. The DNA-bindng site prediction was based on identification of analogs with similar binding sites with BS-score value of $>0.5$.

\section{Results and Discussion}

\section{Identification and characterization of WOX gene family proteins}

WUS gene was the first WOX gene family member identified in Arabidopsis thaliana (AtWUS) and characterized to be involved in meristem maintenance in shoot and floral apices $(6,47)$ and later this gene was shown to regulate floral patterning as well (48). In general, WOX gene family members regulate zygote and embryonic patterning and development, organogenesis, florigenesis and participate in stress responses $(1,3)$. To identify WOX members in Apostasia shenzhenica (AsWOX), extensive BLASTp was carried out and a total of 10 AsWOX protein sequences were identified (Table 1). No splice variants for any of the WOX genes were identified. The size of the WOX gene family in $A$. shenzhenica (10 genes) was comparable with the 


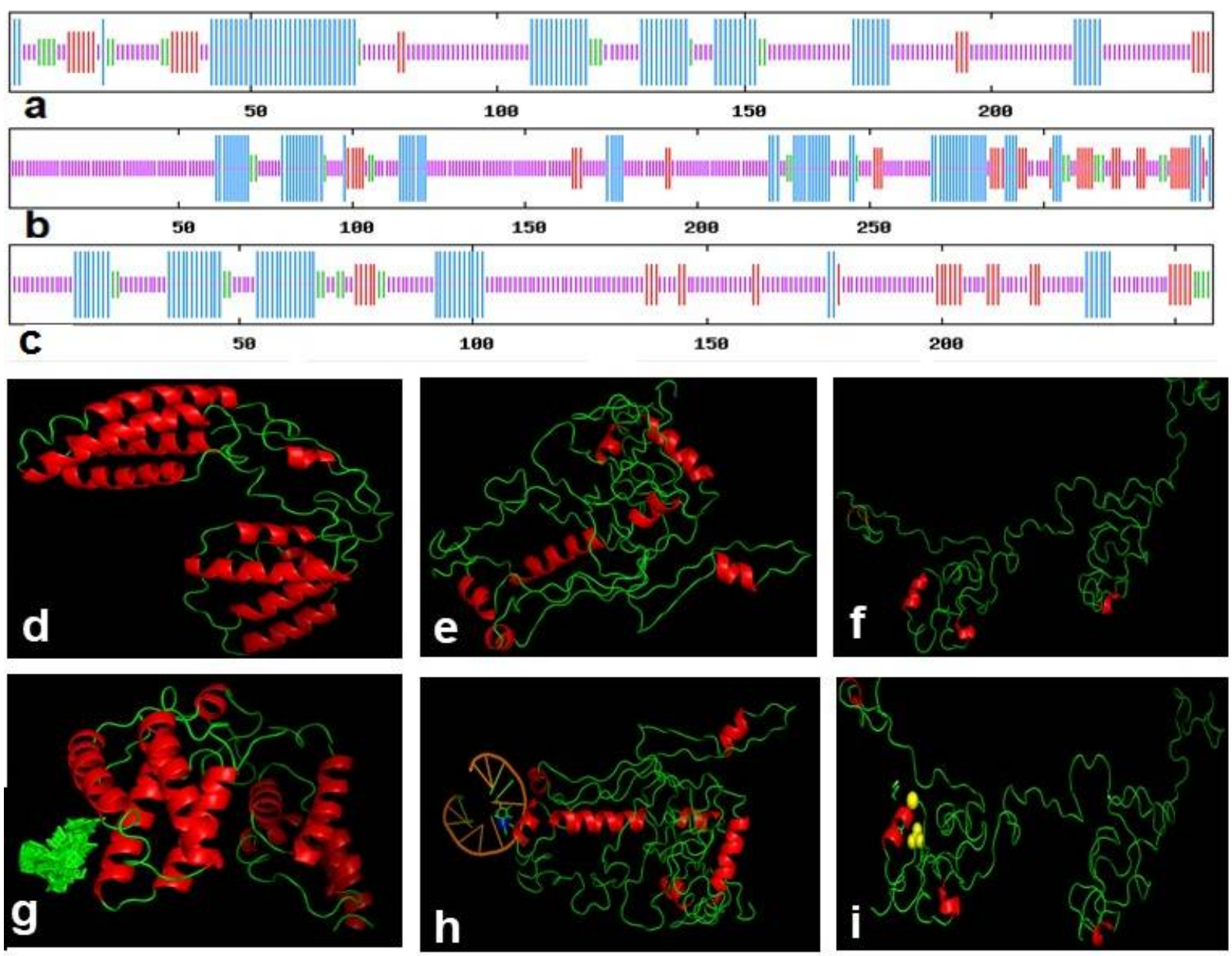

Fig. 5. Structural analysis of AsWOX13, AsWOX9, and AsWOX2B proteins: a,b,c. Secondary structures; d,e,f. Simulated three dimensional structures; g,h,i. Ligand-binding sites.

related orchid species like Phalaenopsis equestris (14 genes, including 3 duplicated genes) and Dendrobium catenatum (10 genes) (19). Multiple sequence alignment indicated that all AsWOXs carry DNAbinding helix-loop-helix-turn-helix region (Fig. 1a). Domain analysis showed that all AsWOX sequences consisted of WUSCHEL-related homeobox domain (helix-loop-helix-turn-helix region) (pfam00046) (Fig. 1b). MEME Suite server identified five conserved motifs, with reduction in evolutionary clade advancement (Fig. 1c).

Phylogenetic analysis for AsWOXs was carried out with those of $D$. catenatum (DcWOXs), P. equestris (PeWOXs), A. thaliana (AtWOXs) and $O$. sativa (OsWOXs), to establish the evolutionary relationships (Fig. 2). Tight clustering of AsWOX13 with PeWOX13A, PeWOX13B, PeWOX13C, DcWOX13 and AtWOX13 revealed that it is a member of ancient clade. Similarly, rest of the genes clustered in the other two clades, Intermediate and WUS, along with the respective sequences of $\mathrm{P}$. equestris, $D$. catenatum, $O$. sativa and $A$. thaliana (Fig. 2).

The peptide length of AsWOXs varied from 137 aa (AsWOX7) to 349 aa (AsWOX9), with an average length of 228 aa (Table 1) which is in sync with reports of Dendrobium catenatum (19). The average molecular weight of AsWOX proteins was $25.03 \mathrm{kDa}$, highest being $37.31 \mathrm{kDa}$ in AsWOX9 and lowest being $16.13 \mathrm{kDa}$ in AsWOX7. The isoelectric point ranged from 5.99 (AsWOX2B) to 10.44 (AsWOX7) with an average of 8.2 and the aliphatic index ranged from 50.08 (AsWOX2B) to 75.05 (AsWOX12) with an average of 63.89 . The grand average of hydropathy (GRAVY) value of all AsWOX proteins had a negative value suggesting their hydrophilic nature (Table 1). No signal peptide or transmembrane helix region was detected in any of the AsWOX protein sequences. These were localised in the nucleus as expected for DNA-binding transcription factors (Table 1) which is in conformity with earlier reports (49).

\section{Gene characterization and duplication events and ortholog prediction}

Genomic scaffold regions for each AsWOXs were identified from the NCBI database and listed (Table 2). The exon-intron gene structure analysis of WOXs showed that three WOX genes (AsWUS, AsWOX9 and AsWOX13) carried two introns, while six genes (AsWOX2A, AsWOX2B, AsWOX3A, AsWOX3B, $A s W O X 11$ and $A s W O X 12)$ were mono-intronic genes and one gene (AsWOX7) was intron less (Fig. 3). Multiple sequence alignment-based sequence similarity index among AsWOX CDS sequences indicated that no gene duplication event occurred within WOX gene family in $A$. shenzhenica genome (Supplementary Table 1) which is in conformity with the results in a related orchid species, $D$. catenatum having 10 WOX genes (19).

The orthologs for each AsWOX were predicted against the sequences of taxonomically closest 
species, $P$. equestris and $D$. catenatum, $A$. thaliana and O. sativa (Table 2 ).

\section{Cis-regulatory elements prediction and Expression analysis}

Detailed analysis revealed that the $1.5 \mathrm{~kb}$ upstream promoter sequences in all the $W O X$ genes carried cisregulatory elements including core promoter elements TATA-box (TATABOX5) and CAAT-box (CAATBOX1), and other elements that direct specific expressions such as, root-specific (ROOTMOTIFTAPOX1, OSE2ROOTNODULE), mesophyll-specific (CACTFTPPCA1), pollen-specific (POLLEN1LELAT52, GTGANTG10), dehydration-esponsive (MYCCONSENSUSAT), light-responsive (IBOXCORE, GT1CONSENSUS), Dof proteins binding domain (DOFCOREZM), WRKY proteins binding W-box (WRKY710S) and wound activating W-box (WBOXNTERF3). In addition, the AGL15 binding element (CARGCW8GAT) and scaffold or matrix attachment region (1 MARTBOX) were predominant (Supplementary Table 2). This reflects the diverse role of WOX genes in plant development. In A. shenzhenica, RNA-seq data was available for three developmental stages i.e. tuber, seed and pollen. AsWOX13, the ancient clade member, showed high expression in all the three developmental stages (Fig. 4). The presence of pollen-specific (POLLEN1LELAT52, GTGANTG10) promoter elements in AsWOX13 suggests a role in anther development, the expression profile of this gene also confirms the same (Fig. 4). This has also been reported in $A$. thaliana, where, the expression of AtWOX13 was found to be higher at floral transition stage, in inflorescences, floral buds, gynoecium and relatively weak expression in fruits and leaves indicating towards its role in flower and embryo development $(7,51)$. It is reported that WOX13 from Physcomitrella patens (PpWOX13) is involved in reprogramming of leaf cells and protoplast cells into stem cells (50). In A. thaliana, AtWOX14, a homologous gene of AtWOX13 gene, is involved in gibberellin synthesis, vascular cell differentiation, floral transtition, anther development and lateral root development (7, 52, 53). The WOX13 genes from Ananas comosus (AcoWOX13), D. catenatum (DcWOX13) and P. equestris (PeWOX13A, PeWOX13B and $P e W O X 13 C$ ) had similar expression pattern (18, 19). The AsWOX9 gene (Fig. 2) had maximum expression in seed (Fig. 4). The promoter region of AsWOX9 carried cis-regulatory elements AACACOREOSGLUB1, 2SSEEDPROTBANAPA, DPBFCOREDCDC3, for seed/embryo specific expression (Table 3). The A. thaliana genes AtWOX9 and AtWOX8 which are phylogenetically closest to AsWOX9, have been reported to play a role in zygote patterning, late embryo development and apical growth $(54,55)$. This suggests that the AsWOX9 gene, with maximum expression in seed could have a role in embryo development. AsWUS showed significant expression in pollen (Fig. 4) which is comparable to the expression profile for WUS gene in P. equestris (19). Earlier reports in $A$. thaliana, indicated the role of AtWUS protein as a repressor in stem cell regulation and an activator in floral patterning (56). AtWUS also promotes vegetative-to-embryonic transition (57) and involves in somatic embryogenesis (58). Promoters of AsWOX9 and AsWUS carried tuber-specific element
(SP8BFIBSP8BIB) and water stress regulated element (MYB2AT). The AsWUS gene promoter carried element (EVENINGAT) for circadian rhythm as well. These observations suggest that AsWUS could possibly play a role in flower development. Another member, $A s W O X 2 B$ gene (Fig. 2), had seed specific expression (Fig. 4). AsWOX2B can be related to the AtWOX2 of $A$. thaliana, which expresses downstream to AtWOX8 and was shown to be involved in zygote patterning and apical growth patterning regulation (54, 55). $A s W O X 2 B$ with seed specific expression might be playing a similar role. All the other WOX genes showed weak expression in tuber, pollen and seed. Promoters of genes AsWOX2A, AsWOX3A, AsWOX9 and $A s W O X 12$ carried elements that interacts with AGAMOUS gene target sequence WUSATAg of intron and that are light-regulated (IBOX). A coupling element (CGACGOSAMY3) for the G box element was found in the promoters of genes AsWOX2A, AsWOX7, $A s W O X 11$ and AsWOX13. Promoters of the genes, AsWOX2B, AsWOX3B, AsWOX9 and AsWOX13 carried (gibberellic acid) GA-responsive element (GAREAT) (Supplementary Table 3). These results support the involvement of WOX gene family in overall plant development.

\section{Protein structure and Homology modeling}

AsWOX13 of ancient clade, AsWOX9 gene of intermediate clade and $A s W O X 2 B$ gene of WUS clade were selected for protein structure simulation and homology modelling, based on high expression profile. These sequences were dominated with random coils ranging from $52.65 \%$ (AsWOX13) to $62.79 \%$ (AsWOX2B) and alpha helix regions ranged from $32.24 \%$ in AsWOX13 to $20.16 \%$ in AsWOX2B (Fig. 5a-C; Table 3). The three-dimensional structure simulation analysis predicted that AsWOX13 and AsWOX9 were nucleic acid binding proteins (Fig. 5d, e, g, h; Table 3), while AsWOX2B was predicted to bind with glycerol (Fig. 5f, i).

\section{Conclusion}

The present study characterizes the WOX gene family in Apostasia shenzhanica. Ten AsWOX genes were identified and grouped into three clades, ancient, intermediate and WUS based on homology modelling with related plants and establishes phylogenetic relationships amongst these. This study opens vistas for functional characterization of AsWOX gene family in various developmental pathways.

\section{Acknowledgements}

Authors are grateful to Department of Science and Technology (DST), Government of India for partial financial support under Promotion of University Research and Scientific Excellence (PURSE) grant scheme. TRR and JKS are thankful to Science and Engineering Research Board (SERB) for NationalPostdoctoral Fellowship (File Number: PDF/2016/003098). MK is thankful to Department of Science and Technology (DST), for INSPIRE fellowship under INSPIRE programme for Junior Research Fellowship (DST/INSPIRE fellowship/2017/IF170940). 


\section{Authors' contribution}

TRR and MK executed the experiments and drafted the manuscript. JKS designed the project, analysed the data and revised the manuscript.

\section{Competing interest}

The authors declared that they have no competing interests.

\section{Supplementary files \\ Supplementary Table 1 \\ Supplementary Table 2 \\ Supplementary Table 3}

\section{References}

1. van der Graaff E, Laux T, Rensing SA. The WUS homeoboxcontaining (WOX) protein family. Genome Biology. 2009;10(12):248. https://doi.org/10.1186/gb-2009-10-12-248

2. Nic-Can GI, Lopez-Torres A, Barredo-Pool F, Wrobel K, LoyolaVargas VM, Rojas-Herrera R, De-la-Pena C. New insights into somatic embryogenesis: LEAFY COTYLEDON1, BABY BOOM1 and WUSCHEL-RELATED HOMEOBOX4 are epigenetically regulated in Coffea canephora. PLoS One. 2013;8(8):e72160. https://doi.org/10.1371/journal.pone.0072160

3. Costanzo E, Trehin C, Vandenbussche M. The role of WOX genes in flower development. Annals of Botany. 2014; 114(7):1545-53. https://doi.org/10.1093/aob/mcu123

4. Gehring WJ, Affolter M, Bürglin T. Homeodomain proteins. Annual Review of Biochemistry. 1994;63(1):487-526. https://doi.org/10.1146/annurev.bi.63.070194.002415

5. Kamiya N, Nagasaki H, Morikami A, Sato Y, Matsuoka M. Isolation and characterization of a rice WUSCHEL-type homeobox gene that is specifically expressed in the central cells of a quiescent center in the root apical meristem. The Plant Journal. 2003;35(4):429-41. https://doi.org/10.1046/j.1365313X.2003.01816.x

6. Laux T, Mayer KF, Berger J, Jurgens G. The WUSCHEL gene is required for shoot and floral meristem integrity in Arabidopsis. Development. 1996;122(1):87-96. https://doi.org/10.1371/journal.pone.0038161

7. Deveaux Y, Toffano-Nioche C, Claisse G, Thareau V, Morin H, Laufs P, Moreau H, Kreis M, Lecharny A. Genes of the most conserved WOX clade in plants affect root and flower development in Arabidopsis. BMC Evolutionary Biology. 2008;8(1):291. https://doi.org/10.1186/1471-2148-8-291

8. Ge Y, Liu J, Zeng M, He J, Qin P, Huang H, Xu L. Identification of WOX family genes in Selaginella kraussiana for studies on stem cells and regeneration in lycophytes. Frontiers in Plant Science. 2016;7:93. https://doi.org/10.3389/fpls.2016.00093

9. Hedman H, Zhu T, von Arnold S, Sohlberg JJ. Analysis of the WUSCHEL-RELATED HOMEOBOX gene family in the conifer Picea abies reveals extensive conservation as well as dynamic patterns. BMC Plant Biology. 2013;13(1):89. https://doi.org/10.1186/1471-2229-13-89

10. Zhang X, Zong J, Liu J, Yin J, Zhang D. Genome-wide analysis of WOX gene family in rice, sorghum, maize, Arabidopsis and poplar. Journal of Integrative plant biology. 2010; 52(11):101626. https://doi.org/10.1111/j.1744-7909.2010.00982.x

11. Li XX, Liu C, Li W, Zhang ZL, Gao XM, Zhou H, Guo YF. Genome-wide identification, phylogenetic analysis and expression profiling of the WOX family genes in Solanum lycopersicum. Yi chuan= Hereditas. 2016;38(5):444-60. http://www.cnki.net/kcms/detail/11.1913.R.20160331.1108.006. html
12. Shchennikova AV, Shulga OA, Kochieva EZ, Beletsky AV, Filyushin MA, Ravin NV, Skryabin KG. Homeobox genes encoding WOX transcription factors in the flowering parasitic plant Monotropa hypopitys. Russian Journal of Genetics: Applied Research. https://doi.org/10.1134/S2079059717070085

13. Tang F, Chen N, Zhao M, Wang Y, He R, Peng X, Shen S. Identification and functional divergence analysis of WOX gene family in paper mulberry. International Journal of Molecular Sciences. 2017;18(8):1782. https://doi.org/10.3390/ijms18081782

14. Cao Y, Han Y, Meng D, Li G, Li D, Abdullah M, Jin Q, Lin Y, Cai Y. Genome-wide analysis suggests the relaxed purifying selection affect the evolution of WOX genes in Pyrus bretschneideri, Prunus persica, Prunus mume and Fragaria vesca. Frontiers in Genetics. 2017;8:78. https://doi.org/10.3389/fgene.2017.00078

15. Li Y, Zhu Y, Yao J, Zhang S, Wang L, Guo C, Van Nocker S, Wang $\mathrm{X}$. Genome-wide identification and expression analyses of the homeobox transcription factor family during ovule development in seedless and seeded grapes. Scientific Reports. 2017;7(1):1-6. https://doi.org/10.1038/s41598-017-12988-y

16. Yang Z, Gong Q, Qin W, Yang Z, Cheng Y, Lu L, Ge X, Zhang C, $\mathrm{Wu} \mathrm{Z}$, Li F. Genome-wide analysis of WOX genes in upland cotton and their expression pattern under different stresses. BMC Plant Biology. 2017;17(1):113. https://doi.org/10.1186/s12870-017-1065-8

17. Zhang N, Huang X, Bao Y, Wang B, Liu L, Dai L, Chen J, An X, Sun Y, Peng D. Genome-wide identification and expression profiling of WUSCHEL-related homeobox (WOX) genes during adventitious shoot regeneration of watermelon (Citrullus lanatus). Acta physiologiae Plantarum. 2015;37(11):224 https://doi.org/10.1007/s11738-015-1964-y

18. Rahman ZU, Azam SM, Liu Y, Yan C, Ali H, Zhao L, Chen P, Yi L, Priyadarshani SV, Yuan Q. Expression profiles of Wuschelrelated homeobox gene family in pineapple (Ananas comosus L.). Tropical Plant Biology. 2017;4(10):204-15 https://doi.org/10.1007/s12042-017-9192-9

19. Ramkumar TR, Kanchan M, Upadhyay SK, Sembi JK Identification and characterization of WUSCHEL-related homeobox (WOX) gene family in economically important orchid species Phalaenopsis equestris and Dendrobium $\begin{array}{llll}\text { catenatum. } & \text { Plant 2018;14:37-45. }\end{array}$ https://doi.org/10.1016/j.plgene.2018.04.004

20. Wang X, Bi C, Wang C, Ye Q, Yin T, Ye N. Genome-wide identification and characterization of WUSCHEL-related homeobox (WOX) genes in Salix suchowensis. Journal of Forestry Research. 2019;30(5):181122.https://doi.org/10.1007/s11676-018-0734-2

21. Wang P, Guo Y, Chen X, Zheng Y, Sun Y, Yang J, Ye N. Genomewide identification of WOX genes and their expression patterns under different hormone and abiotic stress treatments in tea plant (Camellia sinensis). Trees. 2019; 33(4):1129-42. https://doi.org/10.1007/s00468-019-01847-0

22. Li $\mathrm{M}$, Wang $\mathrm{R}$, Liu $\mathrm{Z}$, Wu $\mathrm{X}$, Wang J. Genome-wide identification and analysis of the WUSCHEL-related homeobox (WOX) gene family in allotetraploid Brassica napus reveals changes in WOX genes during polyploidization. BMC Genomics. 2019; 20(1): 317. https://doi.org/10.1186/s12864-0195684-3

23. Chang Y, Song X, Zhang Q, Liu H, Bai Y, Lei X, Pei D. GenomeWide Identification of WOX Gene Family and Expression Analysis during Rejuvenational Rhizogenesis in Walnut

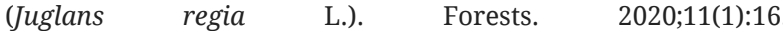
https://doi.org/10.3390/f11010016

24. Cai J, Liu X, Vanneste K, Proost S, Tsai WC, Liu KW, Chen LJ, He $\mathrm{Y}$, Xu Q, Bian C, Zheng Z. The genome sequence of the orchid Phalaenopsis equestris. Nature Genetics. 2015; 47(1): 65-72. https://doi.org/10.1038/ng.3149

25. Zhang GQ, Xu Q, Bian C, Tsai WC, Yeh CM, Liu KW, Yoshida K, Zhang LS, Chang SB, Chen F, Shi Y. The Dendrobium catenatum Lindl. genome sequence provides insights into polysaccharide synthase, floral development and adaptive evolution. Scientific Reports. 2016;6(1):1-10. https://doi.org/10.1038/srep19029

26. Zhang GQ, Liu KW, Li Z, Lohaus R, Hsiao YY, Niu SC, Wang JY, Lin YC, Xu Q, Chen LJ, Yoshida K. The Apostasia genome and 
the evolution of orchids. Nature. 2017;549(7672):379-83. https://doi.org/10.1038/nature23897

27. Givnish TJ, Spalink D, Ames M, Lyon SP, Hunter SJ, Zuluaga A, Iles WJ, Clements MA, Arroyo MT, Leebens-Mack J, Endara L. Orchid phylogenomics and multiple drivers of their extraordinary diversification. Proceedings of the Royal Society B: Biological Sciences. 2015;282(1814):20151553. https://doi.org/10.1098/rspb.2015.1553

28. Schultz J, Copley RR, Doerks T, Ponting CP, Bork P. SMART: a web-based tool for the study of genetically mobile domains. Nucleic Acids Research. 2000;28(1):231-34. https://doi.org/10.1093/nar/28.1.231

29. Sigrist CJ, De Castro E, Cerutti L, Cuche BA, Hulo N, Bridge A, Bougueleret L, Xenarios I. New and continuing developments at PROSITE. Nucleic Acids Research. 2012;41(D1):D344-7. https://doi.org/10.1093/nar/gks1067

30. Corpet F. Multiple sequence alignment with hierarchical clustering. Nucleic Acids Research. 1988;16(22):10881-90. https://doi.org/10.1093/nar/16.22.10881

31. Bailey TL, Boden M, Buske FA, Frith M, Grant CE, Clementi L, Ren J, Li WW, Noble WS. MEME SUITE: tools for motif discovery and searching. Nucleic Acids Research. 2009; 37(suppl_2):W202-8. https://doi.org/10.1093/nar/gkp335

32. Kumar S, Stecher G, Tamura K. MEGA7: molecular evolutionary genetics analysis version 7.0 for bigger datasets. Molecular Biology and Evolution. 2016;33(7):1870-74. https://doi.org/10.1093/molbev/msw054

33. Gasteiger E, Hoogland C, Gattiker A, Duvaud S, Wilkins MR, Appel RD, Bairoch A. Protein identification and analysis tools on the ExPASy server. Springer. 2005:571-607. https://doi.org/10.1385/1-59259-890-0:571

34. Petersen TN, Brunak S, Von Heijne G, Nielsen H. SignalP 4.0: discriminating signal peptides from transmembrane regions. $\begin{array}{llll}\text { Nature } & \text { Methods. } & \text { 2011; } & \text { 8(10): }\end{array}$ https://doi.org/10.1038/nmeth.1701.

35. Krogh A, Larsson B, Von Heijne G, Sonnhammer EL. Predicting transmembrane protein topology with a hidden Markov model: application to complete genomes. Journal of Molecular Biology. https://doi.org/10.1006/jmbi.2000.4315 2001;305(3):567-80.

36. Yu CS, Chen YC, Lu CH, Hwang JK. Prediction of protein subcellular localization. Proteins: Structure, Function, and Bioinformatics. https://doi.org/10.1002/prot.21018

37. Horton P, Park KJ, Obayashi T, Fujita N, Harada H, AdamsCollier CJ, Nakai K. WoLF PSORT: protein localization predictor. Nucleic Acids Research. 2007;35(suppl_2):W585-7. https://doi.org/10.1093/nar/gkm259

38. Emanuelsson O, Nielsen H, Brunak S, Von Heijne G. Predicting subcellular localization of proteins based on their N-terminal amino acid sequence. Journal of Molecular Biology. 2000; 300(4):1005-16. https://doi.org/10.1006/jmbi.2000.3903

39. Chou KC, Shen HB. Plant-mPLoc: a top-down strategy to augment the power for predicting plant protein subcellular localization. PLOS One. 2010;5(6). https://dx.doi.org/10.1371\%2Fjournal.pone.0011335

40. Hu B, Jin J, Guo AY, Zhang H, Luo J, Gao G. GSDS 2.0: an upgraded gene features visualization server. Bioinformatics. 2015;31:1296-97. https://doi.org/10.1093/bioinformatics/btu817

41. Higo K, Ugawa Y, Iwamoto M, Korenaga T. Plant cis-acting regulatory DNA elements (PLACE) database: 1999. Nucleic Acids Research. 1999;27(1):297-300. https://doi.org/10.1093/nar/27.1.297

42. Edgar RC. MUSCLE: multiple sequence alignment with high accuracy and high throughput. Nucleic acids research. 2004;32(5):1792-7. https://doi.org/10.1093/nar/gkh340
43. Mortazavi A, Williams BA, McCue K, Schaeffer L, Wold B. Mapping and quantifying mammalian transcriptomes by RNA$\begin{array}{lll}\text { Seq. } & \text { Nature } & \text { Methods. }\end{array}$ https://doi.org/10.1038/nmeth.1226

44. Seo J, Gordish-Dressman H, Hoffman EP. An interactive power analysis tool for microarray hypothesis testing and generation. Bioinformatics. https://doi.org/10.1093/bioinformatics/btk052

45. Sapay N, Guermeur Y, Deléage G. Prediction of amphipathic inplane membrane anchors in monotopic proteins using a SVM

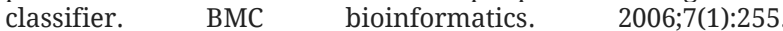
https://dx.doi.org/10.1186\%2F1471-2105-7-255

46. Yang J, Yan R, Roy A, Xu D, Poisson J, Zhang Y. The I-TASSER Suite: protein structure and function prediction. Nature Methods. 2015;12(1):7. https://doi.org/10.1038/nmeth.3213

47. Jha P, Ochatt SJ, Kumar V. WUSCHEL: a master regulator in plant growth signaling. Plant Cell Reports. 2020:1-4. https://doi.org/10.1007/s00299-020-02511-5

48. Colombo L, Battaglia R, Kater MM. Arabidopsis ovule development and its evolutionary conservation. Trends in Plant Science. 2008;13(8):444-50. https://doi.org/10.1016/j.tplants.2008.04.011

49. Mayer KF, Schoof H, Haecker A, Lenhard M, Jürgens G, Laux T. Role of WUSCHEL in regulating stem cell fate in the Arabidopsis shoot meristem. Cell. 1998;95(6):805-15. https://doi.org/10.1016/S0092-8674(00)81703-1

50. Sakakibara K, Reisewitz P, Aoyama T, Friedrich T, Ando S, Sato Y, Tamada Y, Nishiyama T, Hiwatashi Y, Kurata T, Ishikawa M. WOX13-like genes are required for reprogramming of leaf and protoplast cells into stem cells in the moss Physcomitrella patens. Development. 2014;141(8):1660-70. https://doi.org/10.1242/dev.097444

51. Romera-Branchat M, Ripoll JJ, Yanofsky MF, Pelaz S. The WOX 13 homeobox gene promotes replum formation in the Arabidopsis thaliana fruit. The Plant Journal. 2013;73(1):37-49. https://doi.org/10.1111/tpj.12010

52. Etchells JP, Provost CM, Mishra L, Turner SR. WOX4 and WOX14 act downstream of the PXY receptor kinase to regulate plant vascular proliferation independently of any role in vascular organisation. Development. 2013;140(10):2224-34. https://doi.org/10.1242/dev.091314

53. Denis E, Kbiri N, Mary V, Claisse G, Conde e Silva N, Kreis M, Deveaux Y. WOX 14 promotes bioactive gibberellin synthesis and vascular cell differentiation in Arabidopsis. The Plant Journal. 2017;90(3):560-72. https://doi.org/10.1111/tpj.13513

54. Breuninger $\mathrm{H}$, Rikirsch $\mathrm{E}$, Hermann $\mathrm{M}$, Ueda $\mathrm{M}$, Laux $\mathrm{T}$. Differential expression of WOX genes mediates apical-basal axis formation in the Arabidopsis embryo. Developmental Cell. 2008;14(6):867-76. https://doi.org/10.1016/j.devcel.2008.03.008

55. Ueda M, Zhang Z, Laux T. Transcriptional activation of Arabidopsis axis patterning genes WOX8/9 links zygote polarity to embryo development. Developmental cell. 2011;20(2):264 70. https://doi.org/10.1016/j.devcel.2011.01.009

56. Ikeda M, Mitsuda N, Ohme-Takagi M. Arabidopsis WUSCHEL is a bifunctional transcription factor that acts as a repressor in stem cell regulation and as an activator in floral patterning. The Plant Cell. 2009;21(11):3493-505 https://doi.org/10.1105/tpc.109.069997

57. Zuo J, Niu QW, Frugis G, Chua NH. The WUSCHEL gene promotes vegetative-to-embryonic transition in Arabidopsis. The Plant Journal. 2002;30(3):349-59. https://doi.org/10.1046/j.1365-313X.2002.01289.x

58. Su YH, Zhao XY, Liu YB, Zhang CL, O’Neill SD, Zhang XS. Auxininduced WUS expression is essential for embryonic stem cell renewal during somatic embryogenesis in Arabidopsis. The Plant Journal. 2009;59(3):448-60. https://doi.org/10.1111/j.1365313X.2009.03880.x 